\title{
How to make a tuning fork vibrate: the humble pisiform bone
}

\section{A tip for using an old diagnostic tool}

W hile recently observing medical students undertaking an ear, nose and throat examination in an observed structured clinical examination, I watched with interest how each of them attempted to make the tuning fork vibrate. Knowing well that the Rinne and Weber tests were an essential part of the examination technique, they each carefully selected a fork and, almost to a student, proceeded to stumble over the process of making the thing buzz. A couple of students used the heel of their shoe (not particularly decorous), one cracked it on her knee (ouch!), a few tried to squeeze and quickly release the tines (pretty tricky with a C-512 Hz fork), while others, not knowing any better method, gave it a deafening whack on the nearest bit of furniture.

I enquired of myself: how do I usually get a tuning fork to buzz? A quick practical survey of a few senior clinical colleagues in my hospital revealed a similar variety of methods and uncertainty, and caused a certain amount of mirth. My approach - I confess, one I had not given much thought to until now - is to firmly tap the tip of one of the tines on the prominence formed by my opposite pisiform bone (Box).

So, has anyone else shared their experience of a tuning fork tapping technique? For starters, a PubMed search proved unrewarding. However, perusal of several neurology and otorhinolaryngology textbooks was a little more fruitful, revealing just one recommendation on technique: "Tuning forks are activated by striking them lightly against the elbow. The sound generated should not be audible without the fork been held to the ear." ${ }^{11}$ Perhaps the olecranon should be the favoured bony prominence for resonance?

The Latin derivation of pisiform ("pisum", meaning pea) reflects the topography of the bone. Along with the more celebrated scaphoid bone, the pisiform is the most readily palpable of all the carpal bones, disappearing only in full wrist flexion. You can easily locate it when

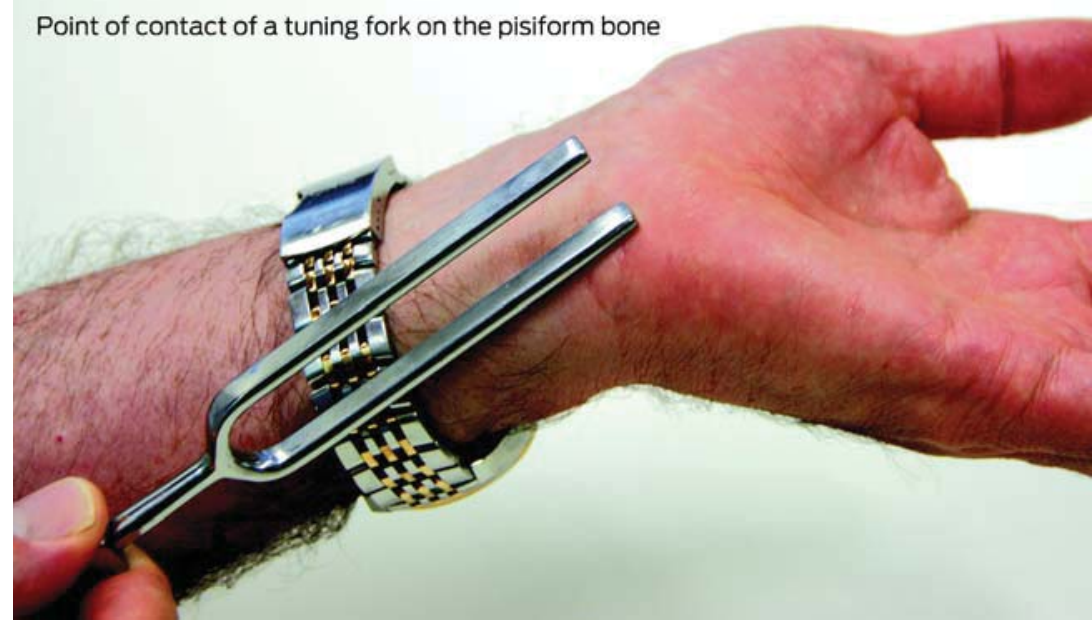

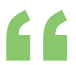

A quick practical survey of a few... colleagues... revealed a similar variety of methods and uncertainty, and caused a certain amount of mirth

D Ashley R Watson MB BS, MPH, FRACP, Chair, Clinical Skills Theme School of Clinical Medicine, Australian National University, Canberra, ACT. ashley.watson@ act.gov.au

doi: 10.5694/mjall.11058 you look at the palm of your hand: find the little bump where the medial end of the distal wrist crease meets the proximal end of your hypothenar eminence. It is the protuberance on which the wrist rests as we manipulate a computer mouse or type at a keyboard - often with the stigma of a small callus. The significance of the bone is reflected in the way it is located largely separately from the plane of the other carpal bones, which also explains why its only articulation is with the deeper lying triquetral bone - a petite pod in which the pea lies.

The bony prominence of the humble pisiform is in my opinion a suitable place to make a tuning fork buzz. In keeping with good pedagogical practice, I propose that some consideration be given to standardising the tuning fork activation method that students are expected to learn, whether pisiform striking, olecranon tapping or percussive use of some other convenient solid object.

Competing interests: No relevant disclosures.

1 Wormald PJ. Clinical examination of the ears and hearing. In: Gleeson M, editor. Scott-Brown's Otorhinolaryngology: head and neck surgery. 7th ed. London: Edward Arnold, 2008: 3317. 